\title{
Enhanced nonlinear optical functionality in birefringence and refractive index dispersion of the deep-ultraviolet fluorooxoborates
}

\author{
Zhihua Yang ${ }^{1,2^{*}}$, Abudukadi Tudi ${ }^{1,2}$, Bing-Hua Lei ${ }^{1,2}$ and Shilie Pan ${ }^{1,2^{*}}$
}

\begin{abstract}
As a promising candidate, the fluorooxoborate has enkindled new explorations of nonlinear optical materials to meet the deep-ultraviolet criteria. However, big challenges and open questions still remain facing this exciting new field, especially the birefringence and dispersion of refractive index which are fundamental parameters for determining the phasematching second harmonic generation wavelength. Here we designed possible anionic groups in fluorooxoborates, and analyzed the optical anisotropy to check its influence on birefringence, which was proved further by the response electronic distribution anisotropy approximation. The functional modules modulating birefringence in fluorooxoborates were explored systematically. We developed an approach for evaluating the behavior of the refractive index dispersions and found that the fluorooxoborates had small refractive index dispersions owing to the introduction of fluorooxoborate modules. Our results demonstrate that fluorooxoborates can be utilized to realize short phase-matching wavelength markedly and offer a path toward novel performance-driven materials design.
\end{abstract}

Keywords: nonlinear optical crystal, deep-ultraviolet, borate, birefringence, phase-matching

\section{INTRODUCTION}

Nonlinear optical (NLO) materials are the vital components of future photoelectric technologies as they can achieve the tunable laser output by the frequency-conversion technology [1-9]. As for deep-ultraviolet (DUV, wavelength $\lambda<200 \mathrm{~nm}$ ) region, the NLO crystals, the unique materials capable of generating DUV coherent light through frequency conversion, are of urgent demands in ultrahigh resolution photolithography, photochemical synthesis, and high-precision micro processing [10-13]. Till now, only $\mathrm{KBe}_{2} \mathrm{BO}_{3} \mathrm{~F}_{2}$ (KBBF) can certainly generate DUV lasers by direct second harmonic generation (SHG), but its application is limited because of the adverse layer growth habit and toxicity issue of containing beryllium [10]. Therefore, the exploration of new DUV NLO materials is in great demand. However, the primary challenge is to balance the three crucial and correlated requirements in one NLO material [12,13]: (i) wide DUV transparency window (a cutoff edge far below $200 \mathrm{~nm}$, or band gap > $6.2 \mathrm{eV}$ ); (ii) relatively large second-order nonlinear coefficient $\left(d_{i j}>1 \times\right.$ commercial $\mathrm{KH}_{2} \mathrm{PO}_{4}$, $\mathrm{KDP}$ ); (iii) sufficient birefringence to satisfy the phasematching (PM) condition in DUV wavelength range.

A promising DUV NLO material should achieve a subtle balance of the correlated criteria. In view of the structure-property relationship, fundamental building units (FBUs) form the 'backbone' of inorganic materials, which, combining their microscopic functionality and arrangement information, greatly influence or even determine their performances [14-20]. For NLO systems, a superior FBU with optimized spatial arrangement, namely a functional module, featured by large HOMOLUMO (the highest occupied molecular orbital and the lowest unoccupied molecular orbital) gap, apparent polarizability anisotropy $(\delta)$ and high hyperpolarizability, will bring benefits to crystals for band gaps, SHG responses, birefringences. In borate systems, a boron atom usually forms a triangle $\left[\mathrm{BO}_{3}\right]$ with $\mathrm{B}-\mathrm{sp}^{2}$ hybridization or

\footnotetext{
${ }^{1}$ CAS Key Laboratory of Functional Materials and Devices for Special Environments, Xinjiang Technical Institute of Physics \& Chemistry, CAS; Xinjiang Key Laboratory of Electronic Information Materials and Devices, Urumqi 830011, China

${ }^{2}$ Center of Materials Science and Optoelectronics Engineering, University of Chinese Academy of Sciences, Beijing 100049, China

* Corresponding authors (emails: slpan@ms.xjb.ac.cn (Pan S); zhyang@ms.xjb.ac.cn (Yang Z))
} 
a tetrahedron $\left[\mathrm{BO}_{4}\right]$ with $\mathrm{B}$-sp ${ }^{3}$ hybridization by linking either three oxygen atoms or four oxygen atoms. As the FBUs in borates, the $\left[\mathrm{BO}_{3}\right]$ and $\left[\mathrm{BO}_{4}\right]$ units may further form rings, chains, layers and three-dimensional (3D) networks by sharing oxygen atoms [21,22]. Because of $\pi$ electron, the planar $\left[\mathrm{BO}_{3}\right]$ unit can be easily polarized, which may render borates a large birefringence or SHG effect. However, considering that the HOMO of the isolated $\left[\mathrm{BO}_{3}\right]$ unit is controlled by the lone pair electrons, one can extend the boron-oxygen framework to increase the polymerization of $\left[\mathrm{BO}_{3}\right]$ to remove the lone pair electrons [23]. Introducing fluorine into borates as a terminal atom is also proved to be one effective way to enlarge the band gap. By introducing fluorine into borates, one can obtain two kinds of compounds: borate fluorides with the fluorine connecting the metal cations and fluorooxoborates with the fluorine also connecting the boron atom. The most typical borate fluorides are KBBF [10,24], $\mathrm{RbBe}_{2} \mathrm{BO}_{3} \mathrm{~F}_{2}$ (RBBF) [25], $\mathrm{BaBe}_{2} \mathrm{BO}_{3} \mathrm{~F}_{3}$ [26], $\mathrm{BaAlBO}_{3} \mathrm{~F}$ [27], $\mathrm{Ba}_{4} \mathrm{~B}_{11} \mathrm{O}_{2} \mathrm{~F}$ [28], $\mathrm{Rb}_{3} \mathrm{Al}_{3} \mathrm{~B}_{3} \mathrm{O}_{10} \mathrm{~F}$ [29], $\mathrm{K}_{3} \mathrm{Sr}_{3} \mathrm{Li}_{2} \mathrm{Al}_{4} \mathrm{~B}_{6} \mathrm{O}_{20} \mathrm{~F}$ [30], $\mathrm{Ca}_{5}\left(\mathrm{BO}_{3}\right)_{3} \mathrm{~F}$ [31], $\mathrm{NaSr}_{3} \mathrm{Be}_{3} \mathrm{~B}_{3} \mathrm{O}_{9} \mathrm{~F}_{4}$ [32], $\mathrm{NH}_{4} \mathrm{Be}_{2} \mathrm{BO}_{3} \mathrm{~F}_{2}$ [33], $\gamma-\mathrm{Be}_{2} \mathrm{BO}_{3} \mathrm{~F}$ [33], and most of them have low UV cutoff edges below $200 \mathrm{~nm}$. However, the KBBF family with the capablility to directly generate DUV coherent light by an SHG process can hardly grow large single crystal due to the layer habit, which hinders the further application. Fluorooxoborates with the $\left[\mathrm{BO}_{x} \mathrm{~F}_{4-x}\right](x=1,2,3)$ groups (represented by [BOF] for simplification), on the other hand, have recently been proved as a new class of promising NLO or optical crystals [34-37]. Among them, $\mathrm{AB}_{4} \mathrm{O}_{6} \mathrm{~F}\left(\mathrm{~A}=\mathrm{NH}_{4}, \mathrm{Cs}\right)$ has the ability to generate DUV coherent light $[34,35]$. Therefore, the $[\mathrm{BOF}]$ groups exhibit promising advantages in the HOMO-LUMO gap and hyperpolarizability, and can further optimize the performance of crystals when combining high-polymerized $\left[\mathrm{BO}_{3}\right]$. As we know, birefringence reflects optical anisotropy induced by the structurally anisotropic confinement [38], which is also one vital factor to determine the PM wavelength [3942]. However, how the fluorine influences the birefringence and the corresponding chromatic dispersion is still unknown. In this work, we analyzed the optical anisotropy distribution of fluorine-containing anionic groups with the aid of molecular design. And the origin of birefringence for the fluorooxoborates was clarified by the response electron distribution anisotropy (REDA) method [43]. Furthermore, the behavior of chromatic dispersion in refractive index was studied. The role of chromatic dispersion in influencing PM wavelength was explored, which can prove the superiority of introducing fluorine to the $\mathrm{B}-\mathrm{O}$ framework.

\section{METHODS}

Polarizability anisotropy $\delta$ was calculated by the density functional theory (DFT) implemented by Gaussian09 package at 6-31G level. We kept the default values of the Gaussian09 code [44] on the aspect of the other calculation parameters and convergence criteria.

The REDA method we proposed previously [43] was used to analyze the contribution of groups to the birefringence. The birefringence is proportional to the REDA index $\xi$ :

$\Delta n \sim \sum_{i}\left[N_{\mathrm{c}} Z_{\mathrm{a}} \Delta \rho_{\mathrm{b}}\right]_{i} /\left(n_{1} E_{\mathrm{g}}\right)$,

where $\xi=\sum_{i}\left[N_{\mathrm{c}} Z_{\mathrm{a}} \Delta \rho_{\mathrm{b}}\right]_{i} /\left(n_{1} E_{\mathrm{g}}\right), N_{\mathrm{c}}$ is the coordination number of the nearest neighbor cations to the central anion, $Z_{\mathrm{a}}$ is the formal chemical valence of the anion, $\Delta \rho_{\mathrm{b}}$ is the difference of covalent electron density of the covalent bond $i$ on the optical principal axes of a crystal, $n_{1}$ is the minimal refractive index, $E_{\mathrm{g}}$ is the optical band gap.

Linear optical properties were calculated by the firstprinciples method based on DFT with generalized gradient approximation (GGA) performed by a plane-wave pseudopotential calculation package CASTEP [45]. We kept the default values of the CASTEP code on the aspect of the calculation parameters and convergence criteria. The linear optical properties were examined via calculating the dielectric function $\varepsilon(\omega)=\varepsilon_{1}(\omega)+i \varepsilon_{2}(\omega)$, where $\varepsilon_{1}(\omega)$ and $\varepsilon_{2}(\omega)$ are the real and imaginary part of dielectric function, respectively. The $\varepsilon_{2}(\omega)$ can be obtained by

$$
\begin{aligned}
\varepsilon_{2}(\omega)= & \frac{4 \pi^{2} e^{2}}{\Omega} \lim _{q \rightarrow 0} \frac{1}{q^{2}} \\
& \times \sum_{c, v, k} 2 \omega_{k} \delta\left(E_{c}-E_{v}-\omega\right)|\langle c|e \cdot q| v\rangle|^{2},
\end{aligned}
$$

where $|\langle c|e \cdot q| v\rangle|$ is the integrated optical transitions from the valance states $(v)$ to the conduction states $(c)$, and the $e, q$ denote the polariozation direction of the photon and electron momentum operator. The real part of the dielectric function $\varepsilon_{1}(\omega)$ can be calculated from $\varepsilon_{2}(\omega)$ based on the Kramers-Kroning transform. And then the refractive indices $n(\omega)$ and the birefrigence $(\Delta n)$ can be calculated accordingly.

\section{RESULTS AND DISCUSSION}

\section{Functionality of fluorine-containing anionic groups}

To date, there are 22 alkali-metal fluorooxoborates and 
one ammonia-fluorooxoborate synthesized mostly by the standard solid-state reaction in sealed silica tubes. And 11 of them take the formula of $\mathrm{A}_{n}\left(\mathrm{~B}_{2} \mathrm{O}_{3}\right)_{m} \mathrm{~F}_{n}(m, n=1,2$, $3, \ldots): \mathrm{LiB}_{6} \mathrm{O}_{9} \mathrm{~F}[46,47], \mathrm{A}_{2} \mathrm{~B}_{6} \mathrm{O}_{9} \mathrm{~F}_{2}(\mathrm{~A}=\mathrm{Li}, \mathrm{Na})[48,49]$, $\mathrm{NaRbB}_{6} \mathrm{O}_{9} \mathrm{~F}_{2}[50], \mathrm{K}_{3} \mathrm{~B}_{6} \mathrm{O}_{9} \mathrm{~F}_{3}[51], \mathrm{AB}_{4} \mathrm{O}_{6} \mathrm{~F}\left(\mathrm{~A}=\mathrm{Na}, \mathrm{NH}_{4}\right.$, $\mathrm{Rb}, \mathrm{Cs})[34,35,52,53], \mathrm{CsKB}_{8} \mathrm{O}_{12} \mathrm{~F}_{2}$ [53], $\mathrm{CsRbB}_{8} \mathrm{O}_{12} \mathrm{~F}_{2}$ [53] with the symmetry of $P n a 2_{1}, C c, P 2_{1} / c, P 2_{1} / n, P 2_{1} / c$, $P n a 2_{1}, P n a 2_{1}, P n a 2_{1}, P 321, P \overline{6} 2 c$. And others are $\mathrm{Li}_{2} \mathrm{~B}_{3} \mathrm{O}_{4} \mathrm{~F}_{3}$ [54], $\mathrm{Li}_{2} \mathrm{Na}_{0.9} \mathrm{~K}_{0.1} \mathrm{~B}_{5} \mathrm{O}_{8} \mathrm{~F}_{2}$ [55], $\mathrm{A}_{3} \mathrm{~B}_{3} \mathrm{O}_{3} \mathrm{~F}_{6}$ ( $\mathrm{A}=$ $\mathrm{Na}, \mathrm{K})[56,57], \mathrm{K}_{0.42} \mathrm{Rb}_{2.58} \mathrm{~B}_{3} \mathrm{O}_{3} \mathrm{~F}_{6}$ [58], $\mathrm{Na}_{0.76} \mathrm{Rb}_{2.24} \mathrm{~B}_{3} \mathrm{O}_{3} \mathrm{~F}_{6}$, $\mathrm{K}_{2}-\mathrm{RbB}_{3} \mathrm{O}_{3} \mathrm{~F}_{6}, \mathrm{~K}_{1.66} \mathrm{Rb}_{1.34} \mathrm{~B}_{3} \mathrm{O}_{3} \mathrm{~F}_{6}, \mathrm{Rb}_{3} \mathrm{~B}_{3} \mathrm{O}_{3} \mathrm{~F}_{6}, \mathrm{KCs}_{2} \mathrm{~B}_{3} \mathrm{O}_{3} \mathrm{~F}_{6}$, $\mathrm{K}_{2.64} \mathrm{Cs}_{0.36} \mathrm{~B}_{3} \mathrm{O}_{3} \mathrm{~F}_{6}$, and $\mathrm{Cs}_{1.29} \mathrm{Rb}_{1.71} \mathrm{~B}_{3} \mathrm{O}_{3} \mathrm{~F}_{6}$ [59], with the symmetry of $P 2_{1} 2_{1} 2_{1}, P b c n, C 2 / c, P 2_{1} / n, P b c n, P 2_{1} / c, P b c n$, $P 2_{1} / c, P 2_{1} / n, P 2_{1} / c, P 2_{1} / c, P 2_{1} / c$. We can see that the symmetry of such fluorooxoborates is various including monoclinic, orthorhombic, trigonal and hexagonal systems. In the known alkali-metal fluorooxoborate family, the FBUs have marked diversity consisting of the combination of $\left[\mathrm{BO}_{3}\right]$, or $\left[\mathrm{BO}_{4}\right]$ with $\left[\mathrm{BO}_{3} \mathrm{~F}\right]$, or $\left[\mathrm{BO}_{2} \mathrm{~F}\right]$, and Table $\mathrm{S} 1$ in the Supplementary Information shows the structural information of typical fluorooxoborates. And to date, only one reported structure consists of " $\left[\mathrm{BOF}_{3}\right]$ " [60], which is hard to be inserted in a six-membered ring (6MR) owing to the terminal fluorine. According to the classification for the FBUs [61,62], the FBUs can be described as $3:\left[\left(3: \mathrm{T}_{2}\right)\right]$ in $\mathrm{Na}_{3} \mathrm{~B}_{3} \mathrm{O}_{3} \mathrm{~F}_{6}$ and $\mathrm{K}_{3} \mathrm{~B}_{3} \mathrm{O}_{3} \mathrm{~F}_{6}, 4:[(3$ $\left.\left.: 2 \Delta+\mathrm{T}_{1}\right)+(1: \Delta)\right]$ in $\mathrm{NH}_{4} \mathrm{~B}_{4} \mathrm{O}_{6} \mathrm{~F}$ and $\mathrm{Rb}_{4} \mathrm{~B}_{4} \mathrm{O}_{6} \mathrm{~F}, 4:[(3:$ $\left.3 \Delta)+\left(1: \mathrm{T}_{1}\right)\right]$ in $\mathrm{CsB}_{4} \mathrm{O}_{6} \mathrm{~F}$, and $6:[(3: 3 \Delta)+(3: 2 \Delta+$ $\left.\left.\mathrm{T}_{1}\right)\right]$ in $\mathrm{LiB}_{6} \mathrm{O}_{9} \mathrm{~F}$, where $\Delta, \mathrm{T}, \mathrm{T}_{0}, \mathrm{~T}_{1}$, and $\mathrm{T}_{2}$ refer to $\left[\mathrm{BO}_{3}\right]$, a general tetrahedra, $\left[\mathrm{BO}_{4}\right],\left[\mathrm{BO}_{3} \mathrm{~F}\right]$, and $\left[\mathrm{BO}_{2} \mathrm{~F}_{2}\right]$, respectively [23]. It is found that the FBUs in the known alkali-metal fluorooxoborate family contain $\mathrm{B}-\mathrm{O}$ or $\mathrm{B}-$ $\mathrm{O}-\mathrm{F}$ 6MR, therefore it is a good maternal microscopicstructure to explore its functionality. As we know, fluorine is the most electronegative and reactive element, so introducing fluorine into the $\mathrm{B}-\mathrm{O}$ groups may provide the advantage of blue-shift of the UV cutoff which is crucial for DUV NLO materials. If we introduce [BOF] into borates, there are three categories of $6 \mathrm{MRs}$ containing [BOF]: [3:2 $2 \Delta+$ T]-type (II), [3: $\Delta+2 \mathrm{~T}]$-type (III), and [3:3T]-type (IV). Fig. 1a shows a classification of the configurations of $6 \mathrm{MRs}$ without considering the direction of fluorine, with $[3: 3 \Delta]$ as type I for com-

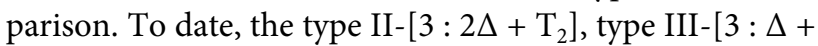
$\left.2 \mathrm{~T}_{2}\right]$ and type III-[3: $\left.\Delta+\mathrm{T}_{0}+\mathrm{T}_{2}\right]$ configurations have not been found in the reported fluorooxoborates. And in type-IV, only $\left[3: \mathrm{T}_{2}\right.$ ] was found in the reported fluorooxoborates. And it is noticed that $\left[\mathrm{BOF}_{3}\right]$ is hard to be embedded into the rings because of the terminal character of fluorine. According to the relationship between local atom groups and NLO properties, NLO functional materials can be characterized by functional modules and fillers [63]. According to the module description, as shown in Fig. 1, in $\mathrm{NH}_{4} \mathrm{~B}_{4} \mathrm{O}_{6} \mathrm{~F}$, the $\left[\mathrm{B}_{3} \mathrm{O}_{6} \mathrm{~F}\right]$ unit with the configuration of $\left[3: \Delta+2 \mathrm{~T}_{1}\right]$ and the $\left[\mathrm{BO}_{3}\right]$ compose $\left[\mathrm{B}_{4} \mathrm{O}_{8} \mathrm{~F}\right]$ and further form the $\mathrm{B}-\mathrm{O}-\mathrm{F}$ layers, and $\mathrm{RbB}_{4} \mathrm{O}_{6} \mathrm{~F}$ has a similar module structure. While for $\mathrm{CsB}_{4} \mathrm{O}_{6} \mathrm{~F}$, the $\left[\mathrm{B}_{4} \mathrm{O}_{8} \mathrm{~F}\right]$ unit consists of $\left[\mathrm{B}_{3} \mathrm{O}_{6}\right]$ and $\left[\mathrm{BO}_{3} \mathrm{~F}\right]$ and also forms the $\mathrm{B}-\mathrm{O}-\mathrm{F}$ layers. The module structures in $\mathrm{NH}_{4} \mathrm{~B}_{4} \mathrm{O}_{6} \mathrm{~F}$ and $\mathrm{CsB}_{4} \mathrm{O}_{6} \mathrm{~F}$ can increase the degree of polymerization, which guarantees the short UV cutoff edges (156 and $155 \mathrm{~nm}$ ). In $\mathrm{Na}_{3} \mathrm{~B}_{3} \mathrm{O}_{3} \mathrm{~F}_{6}$, three $\left[\mathrm{BO}_{2} \mathrm{~F}_{2}\right]$ units form the $\left[\mathrm{B}_{3} \mathrm{O}_{3} \mathrm{~F}_{6}\right] 6 \mathrm{MR}$ with the configuration of [3 : $3 \mathrm{~T}_{2}$ ]. Comparatively, the $\mathrm{B}-\mathrm{O}-\mathrm{F}$ layers with concurrent-parallel $\left[\mathrm{BO}_{3}\right]$ empower the large SHG effect and strong optical anisotropy.

\section{Polarizability characters and microscopic contribution}

To reveal the influence of the possible [BOF] $6 \mathrm{MR}$ on birefringence, we investigated their electronic structure and polarizability characteristics using the DFT method implemented by Gaussian09 package at 6-31G level. The $\delta$ of the designed $6 \mathrm{MRs}$ was investigated, which can reflect the macroscopic birefringence to a certain extent. Fig. 2a shows the $\delta$ along with the HOMO-LUMO gaps. Considering the DUV transparency criterion, the region with the HOMO-LUMO gap larger than $6.2 \mathrm{eV}$ is screened out. And the $\delta$ of $6 \mathrm{MRs}$ in the blue region, larger than $2 \times \delta\left(\mathrm{BO}_{3}\right), \delta\left(\mathrm{B}_{2} \mathrm{O}_{5}\right), 3 \times \delta\left(\mathrm{BO}_{3}\right)$ is highlighted, where the $\left[\mathrm{BO}_{3}\right]$ and its derived structures are birefringence-preferential structures. In particular, the $\left[\mathrm{B}_{2} \mathrm{O}_{5}\right]$ group can be as the benchmark owing to its dominant role in the typical birefringent material $\mathrm{Li}_{2} \mathrm{Na}_{2} \mathrm{~B}_{2} \mathrm{O}_{5}$ with a large birefringence of 0.095 measured via the prism coupling method [64]. It is indicated that the 6MRs with $\delta(6 \mathrm{MRs})$ larger than $\delta\left(\mathrm{B}_{2} \mathrm{O}_{5}\right)$ have the capability to produce large birefringences and possess large HOMO-LUMO gaps as screened out in Fig. 2a.

A hierarchical feature in polarizability anisotropy from I to IV types is shown in Fig. 2b. It can be seen that the groups only containing tetrahedra have the smallest $\delta$. The $\delta$ of $\left[3: 3 \mathrm{~T}_{2}\right]$-FBU, for example, only has $1 / 3$ (or even smaller) times as $[3: 3 \Delta]$, which may indicate that materials only with $\left[3: 3 \mathrm{~T}_{2}\right]$-configuration may have a small birefringence [65]. But we still expect that new materials only with tetrahedral $\mathrm{T}_{2}$-configuration possess a large birefringence. It is feasible because tetrahedral microscopic structures with some optimizing arrangements [63] can lead to large birefringence of materials. When combining $\Delta$ and $\mathrm{T}$, namely, introducing [BOF] forms 


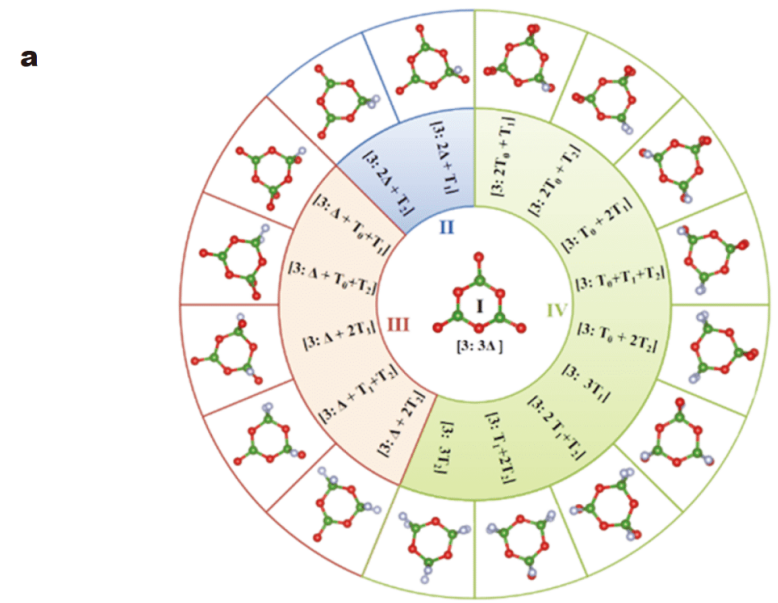

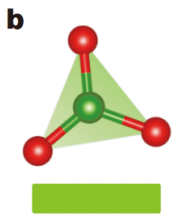

$\mathrm{BO}_{3}$

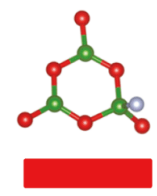

$\mathrm{B}_{3} \mathrm{O}_{6} \mathrm{~F}$

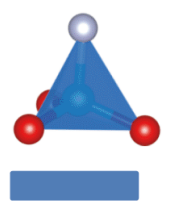

$\mathrm{BO}_{3} \mathrm{~F}$

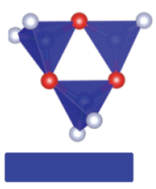

$\mathrm{B}_{3} \mathrm{O}_{3} \mathrm{~F}_{6}$

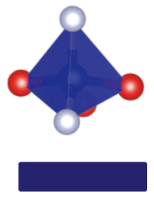

$\mathrm{BO}_{2} \mathrm{~F}_{2}$

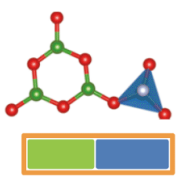

$\mathrm{B}_{4} \mathrm{O}_{8} \mathrm{~F}$

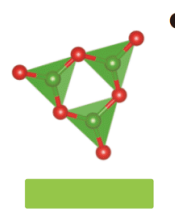

$\mathrm{B}_{3} \mathrm{O}_{6}$

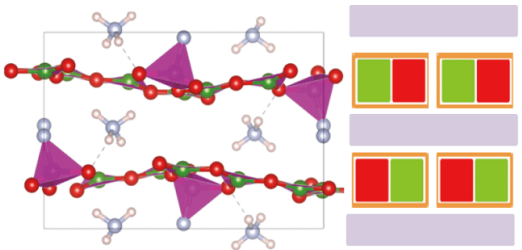

$\mathrm{NH}_{4} \mathrm{~B}_{4} \mathrm{O}_{6} \mathrm{~F}$

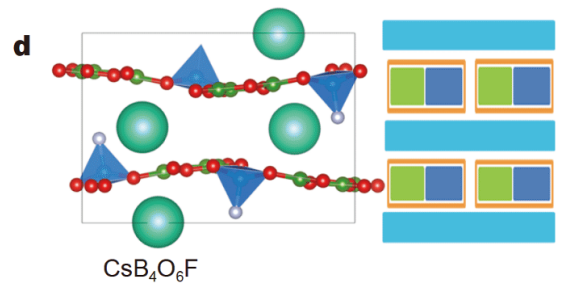

e

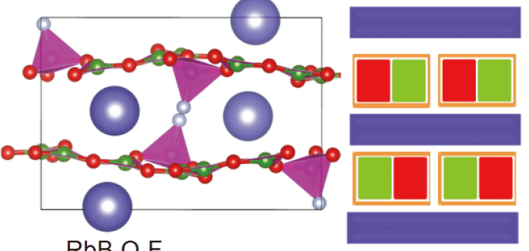

f

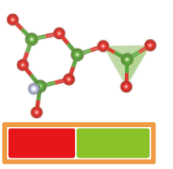

$\mathrm{B}_{4} \mathrm{O}_{8} \mathrm{~F}$

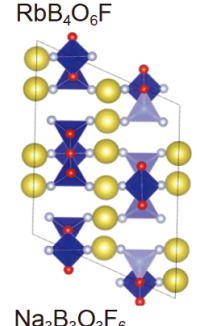

$\mathrm{Na}_{3} \mathrm{~B}_{3} \mathrm{O}_{3} \mathrm{~F}_{6}$

Figure 1 Fluorine-containing 6MRs, functional groups and assembling optical materials with functional groups. (a) Designed 6MR containing [BOF]

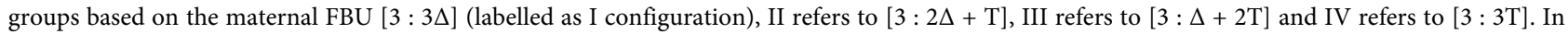
the $[3: 2 \Delta+\mathrm{T}]$-type, only two microstructure configurations exist: $\left[3: 2 \Delta+\mathrm{T}_{1}\right]$, and $\left[3: 2 \Delta+\mathrm{T}_{2}\right]$; in the $[3: \Delta+2 \mathrm{~T}]$-type, there are five kinds of rings: $\left[3: \Delta+2 \mathrm{~T}_{1}\right],\left[3: \Delta+2 \mathrm{~T}_{2}\right],\left[3: \Delta+\mathrm{T}_{1}+\mathrm{T}_{2}\right],\left[3: \Delta+\mathrm{T}_{0}+\mathrm{T}_{1}\right],\left[3: \Delta+\mathrm{T}_{0}+\mathrm{T}_{2}\right]$; and in the $[3: 3 \mathrm{~T}]$-type, there are nine possible rings: $\left[3: 3 \mathrm{~T}_{1}\right],[3$ $\left.: 3 \mathrm{~T}_{2}\right]$, [3:2 $\left.\mathrm{T}_{1}+\mathrm{T}_{2}\right],\left[3: \mathrm{T}_{1}+2 \mathrm{~T}_{1}\right],\left[3: 2 \mathrm{~T}_{0}+\mathrm{T}_{1}\right],\left[3: \mathrm{T}_{0}+2 \mathrm{~T}_{1}\right],\left[3: 2 \mathrm{~T}_{0}+\mathrm{T}_{2}\right],\left[3: \mathrm{T}_{0}+2 \mathrm{~T}_{2}\right]$, and $\left[3: \mathrm{T}_{0}+\mathrm{T}_{1}+\mathrm{T}_{2}\right]$. (b) Typical functional groups in borates, fluorooxoborates used in DUV region. (c) A modular description of $\mathrm{NH}_{4} \mathrm{~B}_{4} \mathrm{O}_{6} \mathrm{~F}$. The $\left[\mathrm{B}_{3} \mathrm{O}_{6} \mathrm{~F}\right]$ units with the configuration of $\left[3: \Delta+2 \mathrm{~T}_{1}\right]$ and $\mathrm{BO}_{3}$ compose the $\mathrm{B}-\mathrm{O}-\mathrm{F}$ layers which guarantee the large SHG effect and strong optical anisotropy. (d) $\mathrm{A}$ modular description of $\mathrm{CsB}_{4} \mathrm{O}_{6} \mathrm{~F}$. The planar $\left[\mathrm{B}_{3} \mathrm{O}_{6}\right]$ and $\left[\mathrm{BO}_{3} \mathrm{~F}\right]$ compose $\mathrm{B}-\mathrm{O}-\mathrm{F}$ layers in crystal structures, which render its strong optical anisotropy and large SHG response. (e) A modular description of $\mathrm{RbB}_{4} \mathrm{O}_{6} \mathrm{~F}$, a similar structure with $\mathrm{NH}_{4} \mathrm{~B}_{4} \mathrm{O}_{6} \mathrm{~F}$. (f) A modular description of $\mathrm{Na}_{3} \mathrm{~B}_{3} \mathrm{O}_{3} \mathrm{~F}_{6}$. Three $\left[\mathrm{BO}_{2} \mathrm{~F}_{2}\right]$ form $\left[\mathrm{B}_{3} \mathrm{O}_{3} \mathrm{~F}_{6}\right] 6 \mathrm{MR}$ with the configuration of $\left[3: 3 \mathrm{~T}_{2}\right]$. Alkali- and alkaline-earth metals are fillers and descripted in one block with colors consistent with the corresponding cation.

$[3: \Delta+2 \mathrm{~T}]$ and $[3: 2 \Delta+\mathrm{T}]$, one can obtain appropriate birefringence. Interestingly, some of $6 \mathrm{MRs}$ with the configuration of $[3: 2 \Delta+\mathrm{T}]$ can have comparable $\delta$ to that of $[3: 3 \Delta]$, the later may produce a large birefringence around 0.12 as in $\beta-\mathrm{BaB}_{2} \mathrm{O}_{4}$. Therefore, the $6 \mathrm{MRs}$ can have a high value of $\delta$ and keep a large HOMO-LUMO gap. Moreover, in the known fluorooxoborates, the $6 \mathrm{MRs}$ connect $\Delta$ or $\mathrm{T}$ to form polymerized 2D B-O-F framework which further enhances the birefringence. The highlighted electronic density of microscopic units also shows the bonding electron distributions from $\mathrm{T}_{2}$ to $\Delta$ and from IV to I in Fig. $2 \mathrm{~b}-\mathrm{g}$. So introducing $[\mathrm{BOF}]$ is beneficial to obtaining a large birefringence that can meet the DUV criterion, while also possessing a wide band gap.

To detect birefringence controlled by the fluorooxoborate units, the REDA method was employed [43]. As shown in Equation (1), it is illustrated that the optical anisotropy is proportional to the REDA index $\xi$. Usually, the changes of the minimal refractive index $n_{1}$ and the band gap $E_{\mathrm{g}}$ bring tiny changes for alkali/alkaline-earth metal borates. Taking $E_{\mathrm{g}}$ for example, a band gap changing from 5.5 to $7.5 \mathrm{eV}$ brings a $5 \%$ difference. Therefore, the birefringence is mainly related to the difference of electron density of anionic groups, namely, $\Delta \rho_{\mathrm{b}}$. Fig. 3 shows the birefringence obtained by the first-principles 

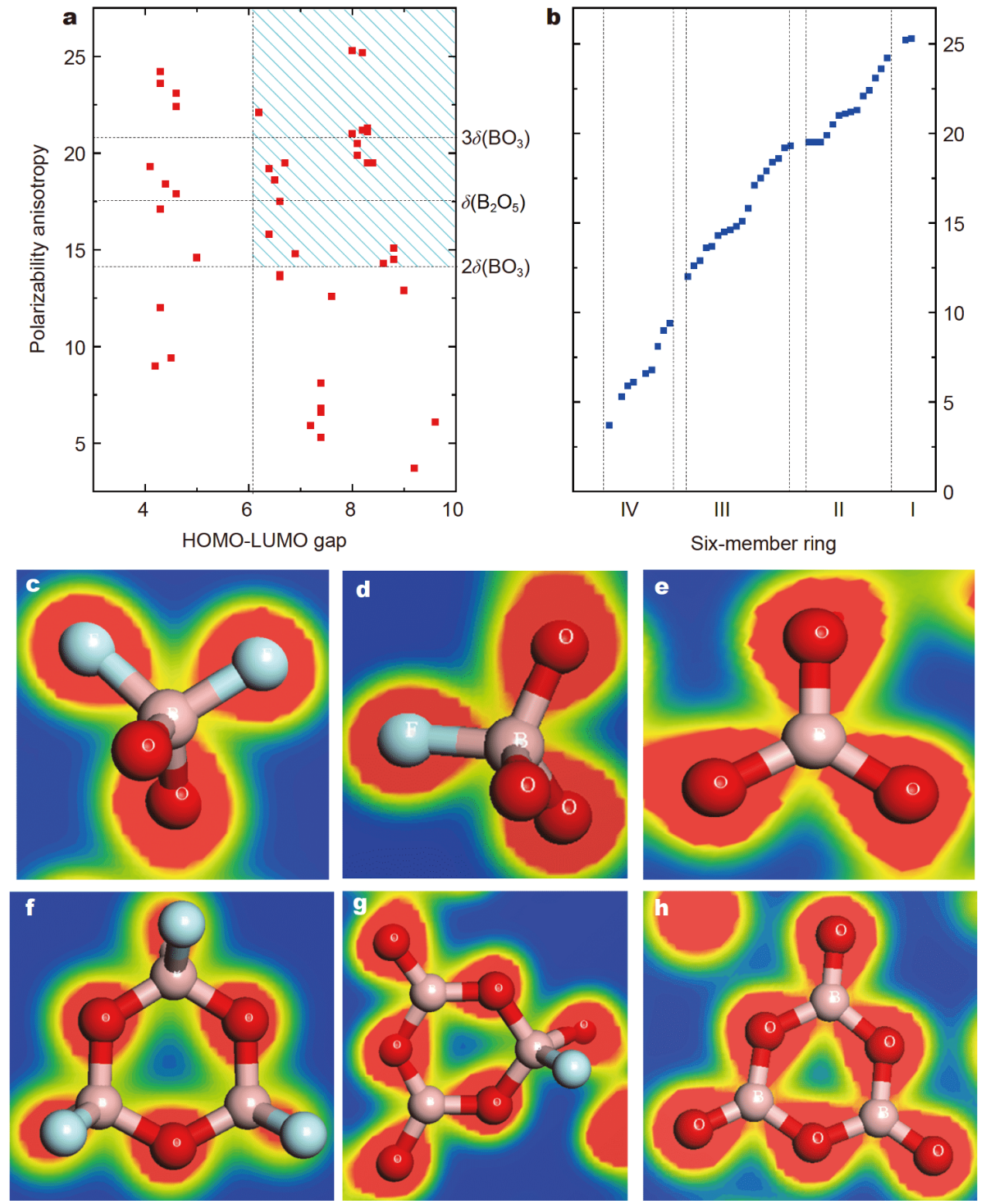

Figure 2 Polarizability anisotropy and highlighted electronic density of microscopic units. (a) $\delta$ of the designed 6MRs as mentioned in Fig. 1a along with the HOMO-LUMO gap. (b) Divided polarizability anisotropy along with different configurations of $6 \mathrm{MRs,}$, where I refers to [ $3: 3 \Delta$ ], II refers to $[3: 2 \Delta+\mathrm{T}]$, III refers to $[3: \Delta+2 \mathrm{~T}]$ and IV refers to $[3: 3 \mathrm{~T}]$. Highlighted electronic density of $\left[\mathrm{BO}_{2} \mathrm{~F}_{2}\right]$ extracted from $\mathrm{Na}_{3} \mathrm{~B}_{3} \mathrm{O}_{3} \mathrm{~F}_{6}(\mathrm{c})$, $\left[\mathrm{BO}_{3} \mathrm{~F}\right]$ extracted from $\mathrm{CsB}_{4} \mathrm{O}_{6} \mathrm{~F}(\mathrm{~d}),\left[\mathrm{BO}_{3}\right]$ extracted from $\mathrm{RbB}_{4} \mathrm{O}_{6} \mathrm{~F}$ (e). Highlighted electronic density of typical $6 \mathrm{MR}$, IV- $\left[\mathrm{B}_{3} \mathrm{O}_{3} \mathrm{~F}_{6}\right]$ extracted from $\mathrm{Na}_{3} \mathrm{~B}_{3} \mathrm{O}_{3} \mathrm{~F}_{6}$ (f), II- $\left[\mathrm{B}_{3} \mathrm{O}_{6} \mathrm{~F}\right]$ extracted from $\mathrm{RbB}_{4} \mathrm{O}_{6} \mathrm{~F}(\mathrm{~g})$, and $\mathrm{I}-\left[\mathrm{B}_{3} \mathrm{O}_{6}\right]$ extracted from $\beta-\mathrm{BaB}_{4} \mathrm{O}_{6}(\mathrm{~h})$.

calculation or experiment of some typical fluorooxoborate materials as well as the difference of electron density of functional modules. One can see that $\mathrm{K}_{3} \mathrm{~B}_{3} \mathrm{O}_{3} \mathrm{~F}_{6}$ with the [3:3T] configuration has a relatively small $\Delta \rho_{\mathrm{b}}$ corresponding to a small birefringence. And $\mathrm{Li}_{2} \mathrm{~B}_{3} \mathrm{O}_{4} \mathrm{~F}_{3}$ with $[3: \Delta+2 \mathrm{~T}]$ has the birefringence about 0.04 , and the compound with $[3: 2 \Delta+\mathrm{T}]$ has a relatively larger birefringence about 0.07 in $\mathrm{Na}_{2} \mathrm{~B}_{6} \mathrm{O}_{9} \mathrm{~F}_{2}$. And $\beta-\mathrm{BaB}_{2} \mathrm{O}_{4}$ with $[3: 3 \Delta], \mathrm{NH}_{4} \mathrm{~B}_{4} \mathrm{O}_{6} \mathrm{~F}$ with $\left[\left(3: 2 \Delta+\mathrm{T}_{1}\right)+(1: \Delta)\right]$ and $\mathrm{CsB}_{4} \mathrm{O}_{6} \mathrm{~F}$ with $\left[(3: 3 \Delta)+\left(1: \mathrm{T}_{1}\right)\right]$ have comparable and large birefringences [66]. Therefore, it proves that different birefringences in the discussed borates and fluorooxoborates are mainly attributed to the different configurations in the anionic groups such as $6 \mathrm{MR}$ configurations (I-IV). And introducing fluorine can adjust the birefringence into a suitable region.

\section{Dispersion of refractive index in affecting PM condition} As an NLO material, the ability of PM is crucial because it determines the applied shortest PM SHG wavelength and 


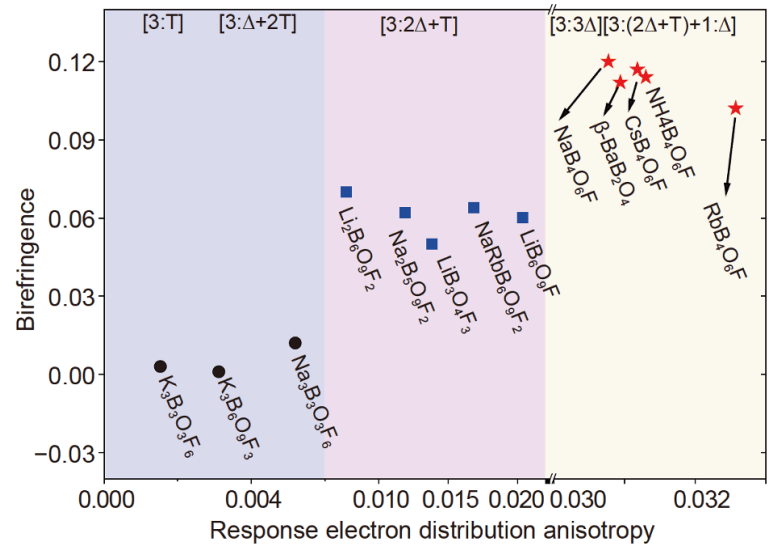

Figure 3 Birefringences obtained by the first-principles calculation or experiment of typical fluorooxoborate materials with respective to the response electron distribution anisotropy $\Delta \rho^{b}$ of fluorooxoborate units.

SHG efficiency of the crystal [39]. Dispersion of refractive index is a vital factor for PM in SHG process. Small dispersion is preferred as it will give a short SHG wavelength. We define the dispersion characteristic factor as

$D(\lambda)=\frac{n_{\min }(\lambda / 2)}{n_{\max }(\lambda)}$.

Therefore, when the dispersion characteristic factor $D(\lambda)=1$, we can get the shortest PM SHG wavelength $\lambda \mathrm{s}^{\mathrm{PM}}$. According to our previous research [43,63], $D(\lambda)$ is related to,

$D(\lambda)=\sqrt{1+\frac{\left[\left(n_{\max }(\lambda)-\Delta n\right)^{2}-1\right]\left(\lambda^{2}-R \lambda_{c}^{2}\right)}{\lambda^{2}-4 R \lambda_{c}^{2}}} / n_{\max }(\lambda)$,

where, $\lambda_{c}$ is determined by natural resonant frequency. Fig. 4a, b and Fig. S1 give the consistent results from Equations (3) and (4). At the PM wavelength, $D(\lambda)=1$, from which the shortest PM wavelength $\lambda \mathrm{s}^{\mathrm{PM}}$ can be obtained. In the PM region, $D(\lambda)<1$ while in the nonphase-matching (NPM) region, $D(\lambda)>1$. And we can also see that a larger band gap or a shorter UV cutoff edge is beneficial to a flatter dispersion at a given wavelength. It can be checked directly from the Sellmeier equations $[20,30,34,35,66]$, as shown in Fig. $4 \mathrm{~b}$ and Fig. S1. $\mathrm{NH}_{4} \mathrm{~B}_{4} \mathrm{O}_{6} \mathrm{~F}$ has a shorter $\lambda \mathrm{s}^{\mathrm{PM}}$, although it has a slightly smaller birefringence as compared with $\beta-\mathrm{BaB}_{2} \mathrm{O}_{4}$. In fact, the factors inducing a shorter $\lambda \mathrm{s}^{\mathrm{PM}}$, besides the large band gap and birefringence, including a small chromatic dispersion of refractive index, are also crucial.

A small dispersion is beneficial to realizing the angle PM to a shorter SHG wavelength as described above. Based on the dispersion equation, the birefringence, the refractive index and band gap have influences on the dispersion. One can see that the variation of the refractive index is small. Therefore, the dispersion is mainly determined by birefringence and band gap. This is also verified by the results shown in Fig. S2. In general, the materials with large band gap or birefringence always have smaller dispersion at an identical wavelength. Although KBBF has relatively small birefringence, the large band gap facilitates its PM in DUV region. It is because $\mathrm{NH}_{4} \mathrm{~B}_{4} \mathrm{O}_{6} \mathrm{~F}$ has a short $\mathrm{PM}$ wavelength owing to its large birefringence and wide band gap, which is proved by the experimental results as shown in Fig. S3. The angle PM can be realized by the optical anisotropy as well as the frequency dispersion.

\section{CONCLUSIONS}

In summary, we studied the influencing factors to control the birefringence and the dispersion of refractive index of recent DUV fluorooxoborates by estimating a dispersion characteristic factor. It reveals that the fluorooxoborates possess strong optical anisotropy due to large covalent
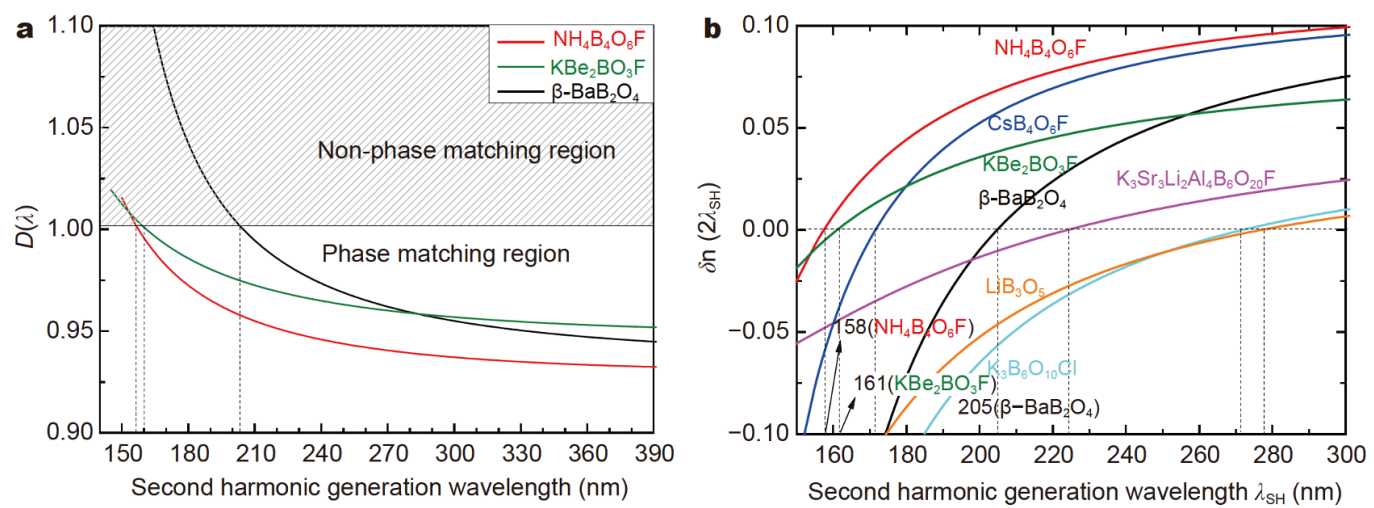

Figure 4 (a) Refractive index dispersion of different NLO borates, from the borate $\beta-\mathrm{BaB}_{2} \mathrm{O}_{4}$ to the borate fluoride $\mathrm{KBe}_{2} \mathrm{BO}_{3} \mathrm{~F}_{2}$ and the fluorooxoborate $\mathrm{NH}_{4} \mathrm{~B}_{4} \mathrm{O}_{6} \mathrm{~F}$. (b) The shortest PM SHG wavelength based on the corresponding Sellmeier equation. 
response electronic distribution induced by the $\mathrm{B}-\mathrm{O}$ or $\mathrm{B}-\mathrm{O}-\mathrm{F}$ rings and the corresponding quasi-layer arrangement. By exploring the 6MRs (including newly designed ones), it is found that introducing different numbers of fluorine atoms into the ring can modulate the polarizability anisotropy and accordingly influence the birefringence. Furthermore, introducing fluorine into $\mathrm{B}-\mathrm{O}$ groups can reduce the chromatic dispersion of refractive indices which is beneficial to a shorter PM wavelength. It further proves our previous assumption that the $[\mathrm{BOF}]$ group is one kind of superior basic units. Under the analysis of the structures, the designed possible six-membered [BOF] rings can be regarded as new fundamental units to form diverse materials. We hope that this work will be useful in guiding the novel performancedriven materials design.

\section{Received 30 January 2020; accepted 24 February 2020; published online 20 March 2020}

1 Savage N. Ultraviolet lasers. Nat Photon, 2007, 1: 83-85

2 Eaton DF. Nonlinear optical materials. Science, 1991, 253: 281-287

3 Cyranoski D. Materials science: China's crystal cache. Nature, 2009, 457: 953-955

4 Xia Z, Poeppelmeier KR. Chemistry-inspired adaptable framework structures. Acc Chem Res, 2017, 50: 1222-1230

5 Huang J, Guo S, Zhang Z, et al. Designing excellent mid-infrared nonlinear optical materials with fluorooxo-functional group of $\mathrm{d}^{0}$ transition metal oxyfluorides. Sci China Mater, 2019, 62: 1798-1806

6 Huppertz $\mathrm{H}$, von der Eltz B. Multianvil high-pressure synthesis of $\mathrm{Dy}_{4} \mathrm{~B}_{6} \mathrm{O}_{15}$ : The first oxoborate with edge-sharing $\mathrm{BO}_{4}$ tetrahedra. J Am Chem Soc, 2002, 124: 9376-9377

7 Dong X, Huang L, Hu C, et al. $\mathrm{CsSbF}_{2} \mathrm{SO}_{4}$ : An Excellent ultraviolet nonlinear optical sulfate with a $\mathrm{KTiOPO}_{4}(\mathrm{KTP})$-type structure. Angew Chem Int Ed, 2019, 58: 6528-6534

8 Xie Z, Wang Y, Cheng S, et al. Synthesis, characterization, and theoretical analysis of three new nonlinear optical materials $\mathrm{K}_{7} \mathrm{MRE}_{2} \mathrm{~B}_{15} \mathrm{O}_{30}(\mathrm{M}=\mathrm{Ca}$ and $\mathrm{Ba}, \mathrm{RE}=\mathrm{La}$ and $\mathrm{Bi})$. Sci China Mater, 2019, 62: 1151-1161

9 Wang $\mathrm{Z}$, He J, Hu B, et al. $\mathrm{Ca}_{2} \mathrm{~B}_{5} \mathrm{O}_{9} \mathrm{Cl}$ and $\mathrm{Sr}_{2} \mathrm{~B}_{5} \mathrm{O}_{9} \mathrm{Cl}$ : Nonlinear optical crystals with deep-ultraviolet transparency windows. ACS Appl Mater Interfaces, 2020, 12: 4632-4637

10 Chen CT, Wang GL, Wang XY, et al. Deep-UV nonlinear optical crystal $\mathrm{KBe}_{2} \mathrm{BO}_{3} \mathrm{~F}_{2}$ - discovery, growth, optical properties and applications. Appl Phys B, 2009, 97: 9-25

11 Chen C, Ye N, Lin J, et al. Computer-assisted search for nonlinear optical crystals. Adv Mater, 1999, 11: 1071-1078

12 Yao W, He R, Wang X, et al. Analysis of deep-UV nonlinear optical borates: approaching the end. Adv Opt Mater, 2014, 2: 411417

13 Halasyamani PS, Rondinelli JM. The must-have and nice-to-have experimental and computational requirements for functional frequency doubling deep-UV crystals. Nat Commun, 2018, 9: 2972

14 Chang HY, Kim SH, Halasyamani PS, et al. Alignment of lone pairs in a new polar material: synthesis, characterization, and functional properties of $\mathrm{Li}_{2} \mathrm{Ti}\left(\mathrm{IO}_{3}\right)_{6}$. J Am Chem Soc, 2009, 131: 2426-2427
15 Ok KM, Chi EO, Halasyamani PS. Bulk characterization methods for non-centrosymmetric materials: second-harmonic generation, piezoelectricity, pyroelectricity, and ferroelectricity. Chem Soc Rev, 2006, 35: 710-717

16 Halasyamani PS. Asymmetric cation coordination in oxide materials: influence of lone-pair cations on the intra-octahedral distortion in $\mathrm{d}^{0}$ transition metals. Chem Mater, 2004, 16: 3586-3592

17 Halasyamani PS, Poeppelmeier KR. Preface: Overview of the forum on functional inorganic materials. Inorg Chem, 2008, 47: 84278428

18 Zhou G, Guo S, Zhao J, et al. Unraveling the mechanochemical synthesis and luminescence in $\mathrm{Mn}^{\mathrm{II}}$-based two-dimensional hybrid perovskite $\left(\mathrm{C}_{4} \mathrm{H}_{9} \mathrm{NH}_{3}\right)_{2} \mathrm{PbCl}_{4}$. Sci China Mater, 2019, 62: 10131022

19 Huang YZ, Wu LM, Wu XT, et al. $\mathrm{Pb}_{2} \mathrm{~B}_{5} \mathrm{O}_{9} \mathrm{I}$ : An iodide borate with strong second harmonic generation. J Am Chem Soc, 2010, 132: 12788-12789

$20 \mathrm{Wu} \mathrm{H}$, Pan S, Poeppelmeier KR, et al. $\mathrm{K}_{3} \mathrm{~B}_{6} \mathrm{O}_{10} \mathrm{Cl}$ : A new structure analogous to perovskite with a large second harmonic generation response and deep UV absorption edge. J Am Chem Soc, 2011, 133: 7786-7790

21 Cao GJ, Wei Q, Cheng JW, et al. A zeolite CAN-type aluminoborate with gigantic 24-ring channels. Chem Commun, 2016, 52: 1729-1732

22 Liang F, Kang L, Gong P, et al. Rational design of deep-ultraviolet nonlinear optical materials in fluorooxoborates: toward optimal planar configuration. Chem Mater, 2017, 29: 7098-7102

23 Yang Z, Lei BH, Zhang W, et al. Module-analysis-assisted design of deep ultraviolet fluorooxoborates with extremely large gap and high structural stability. Chem Mater, 2019, 31: 2807-2813

24 Wu B, Tang D, Ye N, et al. Linear and nonlinear optical properties of the $\mathrm{KBe}_{2} \mathrm{BO}_{3} \mathrm{~F}_{2}$ (KBBF) crystal. Optical Mater, 1996, 5: 105-109

25 Chen C, Luo S, Wang X, et al. Deep UV nonlinear optical crystal: $\mathrm{RbBe}_{2}\left(\mathrm{BO}_{3}\right) \mathrm{F}_{2}$. J Opt Soc Am B, 2009, 26: 1519-1525

26 Guo S, Jiang $\mathrm{X}$, Liu L, et al. $\mathrm{BaBe}_{2} \mathrm{BO}_{3} \mathrm{~F}_{3}$ : A KBBF-type deepultraviolet nonlinear optical material with reinforced $\left[\mathrm{Be}_{2} \mathrm{BO}_{3} \mathrm{~F}_{2}\right]_{\infty}$ layers and short phase-matching wavelength. Chem Mater, 2016, 28: 8871-8875

27 Hu Z, Yue Y, Chen X, et al. Growth and structure redetermination of a nonlinear $\mathrm{BaAlBO}_{3} \mathrm{~F}_{2}$ crystal. Solid State Sci, 2011, 13: 875-878

$28 \mathrm{Wu} \mathrm{H}, \mathrm{Yu} \mathrm{H}$, Yang Z, et al. Designing a deep-ultraviolet nonlinear optical material with a large second harmonic generation response. J Am Chem Soc, 2013, 135: 4215-4218

29 Zhao S, Gong $\mathrm{P}$, Luo $\mathrm{S}$, et al. Beryllium-free $\mathrm{Rb}_{3} \mathrm{Al}_{3} \mathrm{~B}_{3} \mathrm{O}_{10} \mathrm{~F}$ with reinforced interlayer bonding as a deep-ultraviolet nonlinear optical crystal. J Am Chem Soc, 2015, 137: 2207-2210

$30 \mathrm{Wu} \mathrm{H}, \mathrm{Yu} \mathrm{H}$, Pan S, et al. Deep-ultraviolet nonlinear-optical material $\mathrm{K}_{3} \mathrm{Sr}_{3} \mathrm{Li}_{2} \mathrm{Al}_{4} \mathrm{~B}_{6} \mathrm{O}_{20} \mathrm{~F}$ : Addressing the structural instability problem in $\mathrm{KBe}_{2} \mathrm{BO}_{3} \mathrm{~F}_{2}$. Inorg Chem, 2017, 56: 8755-8758

$31 \mathrm{Xu} \mathrm{K}$, Loiseau $\mathrm{P}$, Aka $\mathrm{G}$, et al. Nonlinear optical properties of $\mathrm{Ca}_{5}\left(\mathrm{BO}_{3}\right)_{3} \mathrm{~F}$ crystal. Opt Express, 2008, 16: 17735-17744

32 Huang $\mathrm{H}$, Yao J, Lin $\mathrm{Z}$, et al. $\mathrm{NaSr}_{3} \mathrm{Be}_{3} \mathrm{~B}_{3} \mathrm{O}_{9} \mathrm{~F}_{4}$ : A Promising deepultraviolet nonlinear optical material resulting from the cooperative alignment of the $\left[\mathrm{Be}_{3} \mathrm{~B} 3 \mathrm{O}_{12} \mathrm{~F}\right]^{10-}$ anionic group. Angew Chem Int Ed, 2011, 50: 9141-9144

33 Peng G, Ye N, Lin Z, et al. $\mathrm{NH}_{4} \mathrm{Be}_{2} \mathrm{BO}_{3} \mathrm{~F}_{2}$ and $\gamma-\mathrm{Be}_{2} \mathrm{BO}_{3} \mathrm{~F}$ : Overcoming the layering habit in $\mathrm{KBe}_{2} \mathrm{BO}_{3} \mathrm{~F}_{2}$ for the next-generation deep-ultraviolet nonlinear optical materials. Angew Chem Int Ed, 2018, 57: 8968-8972

34 Shi G, Wang Y, Zhang F, et al. Finding the next deep-ultraviolet 
nonlinear optical material: $\mathrm{NH}_{4} \mathrm{~B}_{4} \mathrm{O}_{6} \mathrm{~F}$. J Am Chem Soc, 2017, 139: 10645-10648

35 Wang $\mathrm{X}$, Wang $\mathrm{Y}$, Zhang $\mathrm{B}$, et al. $\mathrm{CsB}_{4} \mathrm{O}_{6} \mathrm{~F}$ : A congruent-melting deep-ultraviolet nonlinear optical material by combining superior functional units. Angew Chem Int Ed, 2017, 56: 14119-14123

36 Mutailipu M, Zhang $\mathrm{M}$, Zhang $\mathrm{B}$, et al. $\mathrm{SrB}_{5} \mathrm{O}_{7} \mathrm{~F}_{3}$ functionalized with $\left[\mathrm{B}_{5} \mathrm{O}_{9} \mathrm{~F}_{3}\right]^{6-}$ chromophores: Accelerating the rational design of deep-ultraviolet nonlinear optical materials. Angew Chem Int Ed, 2018, 57: 6095-6099

37 Jantz SG, Pielnhofer F, van Wüllen L, et al. The first alkaline-earth fluorooxoborate $\mathrm{Ba}\left[\mathrm{B}_{4} \mathrm{O}_{6} \mathrm{~F}_{2}\right]$-characterisation and doping with $\mathrm{Eu}^{2+}$. Chem Eur J, 2018, 24: 443-450

38 Chen X, Zhang B, Zhang F, et al. Designing an excellent deepultraviolet birefringent material for light polarization. J Am Chem Soc, 2018, 140: 16311-16319

39 Halasyamani PS, Zhang W. Viewpoint: inorganic materials for UV and deep-UV nonlinear-optical applications. Inorg Chem, 2017, 56: $12077-12085$

40 Zhang B, Tikhonov E, Xie C, et al. Prediction of fluorooxoborates with colossal second harmonic generation (SHG) coefficients and extremely wide band gaps: towards modulating properties by tuning the $\mathrm{BO}_{3} / \mathrm{BO}_{3} \mathrm{~F}$ ratio in layers. Angew Chem Int Ed, 2019, 58: $11726-11730$

41 Zhao S, Gong P, Bai L, et al. Beryllium-free $\mathrm{Li}_{4} \mathrm{Sr}\left(\mathrm{BO}_{3}\right)_{2}$ for deepultraviolet nonlinear optical applications. Nat Commun, 2014, 5: 4019

42 Lu H, Gautier R, Donakowski MD, et al. Nonlinear active materials: An illustration of controllable phase matchability. J Am Chem Soc, 2013, 135: 11942-11950

43 Lei BH, Yang Z, Pan S. Enhancing optical anisotropy of crystals by optimizing bonding electron distribution in anionic groups. Chem Commun, 2017, 53: 2818-2821

44 Frisch MJ, Trucks GW, Schlegel HB, et al. Gaussian 09, revision C.01. Gaussian Inc.: Wallingford, CT, 2009

45 Clark SJ, Segall MD, Pickard CJ, et al. First principles methods using CASTEP. Z für Kristallographie - Crystline Mater, 2005, 220: 567-570

46 Cakmak G, Nuss J, Jansen $\mathrm{M}$. $\mathrm{LiB}_{6} \mathrm{O}_{9} \mathrm{~F}$, the first lithium fluorooxoborate-crystal structure and ionic conductivity. Z Anorg Allg Chem, 2009, 635: 631-636

47 Zhang B, Shi G, Yang Z, et al. Fluorooxoborates: beryllium-free deep-ultraviolet nonlinear optical materials without layered growth. Angew Chem Int Ed, 2017, 56: 3916-3919

48 Pilz T, Jansen M. $\mathrm{Li}_{2} \mathrm{~B}_{6} \mathrm{O}_{9} \mathrm{~F}_{2}$, a new acentric fluorooxoborate. $\mathrm{Z}$ Anorg Allg Chem, 2011, 637: 2148-2152

49 Shi G, Zhang F, Zhang B, et al. $\mathrm{Na}_{2} \mathrm{~B}_{6} \mathrm{O}_{9} \mathrm{~F}_{2}$ : A fluoroborate with short cutoff edge and deep-ultraviolet birefringent property prepared by an open high-temperature solution method. Inorg Chem, 2017, 56: 344-350

50 Han $\mathrm{S}$, Zhang $\mathrm{B}$, Yang $\mathrm{Z}$, et al. From $\mathrm{LiB}_{3} \mathrm{O}_{5}$ to $\mathrm{NaRbB}_{6} \mathrm{O}_{9} \mathrm{~F}_{2}$ : Fluorine-directed evolution of structural chemistry. Chem Eur J, 2018, 24: 10022-10027

51 Han G, Shi G, Wang Y, et al. $\mathrm{K}_{3} \mathrm{~B}_{6} \mathrm{O}_{9} \mathrm{~F}_{3}$ : A new fluorooxoborate with four different anionic units. Chem Eur J, 2018, 24: 4497-4502

52 Zhang Z, Wang $\mathrm{Y}$, Zhang B, et al. Polar fluorooxoborate, $\mathrm{NaB}_{4} \mathrm{O}_{6} \mathrm{~F}$ : A promising material for ionic conduction and nonlinear optics. Angew Chem Int Ed, 2018, 57: 6577-6581

53 Wang Y, Zhang B, Yang Z, et al. Cation-tuned synthesis of fluorooxoborates: towards optimal deep-ultraviolet nonlinear optical materials. Angew Chem Int Ed, 2018, 57: 2150-2154

54 Pilz $\mathrm{T}$, Nuss $\mathrm{H}$, Jansen $\mathrm{M}$. $\mathrm{Li}_{2} \mathrm{~B}_{3} \mathrm{O}_{4} \mathrm{~F}_{3}$, a new lithium-rich fluorooxoborate. J Solid State Chem, 2012, 186: 104-108

55 Han $\mathrm{S}$, Wang $\mathrm{Y}$, Zhang $\mathrm{B}$, et al. A member of fluorooxoborates: $\mathrm{Li}_{2} \mathrm{Na}_{0.9} \mathrm{~K}_{0.1} \mathrm{~B}_{5} \mathrm{O}_{8} \mathrm{~F}_{2}$ with the fundamental building block $\mathrm{B}_{5} \mathrm{O}_{10} \mathrm{~F}_{2}$ and a short cutoff edge. Inorg Chem, 2018, 57: 873-878

56 Cakmak G, Pilz T, Jansen M. $\mathrm{Na}_{3} \mathrm{~B}_{3} \mathrm{O}_{3} \mathrm{~F}_{6}$ : Synthesis, crystal structure, and ionic conductivity. Z Anorg Allg Chem, 2012, 638: 14111415

$57 \mathrm{Wu} \mathrm{H}, \mathrm{Yu} \mathrm{H}$, Bian Q, et al. Borate fluoride and fluoroborate in alkali-metal borate prepared by an open high-temperature solution method. Inorg Chem, 2014, 53: 12686-12688

58 Jiang D, Han G, Wang Y, et al. Designing three fluorooxoborates with a wide transmittance window by anionic group substitution. Inorg Chem, 2019, 58: 3596-3600

59 Zhang W, Wei Z, Yang Z, et al. Cation modulation on the crystal structure and band gap of fluorooxoborates $\mathrm{A}_{3} \mathrm{~B}_{3} \mathrm{O}_{3} \mathrm{~F}_{6}(\mathrm{~A}=$ alkali and mixed alkali metal). Inorg Chem, 2019, 58: 13411-13417

60 Chackraburtty DM. The structure of $\mathrm{BaBOF}_{3}$. Acta Cryst, 1957, 10: 199-200

61 Burns PC, Grice JD, Hawthorne FC. Borate minerals. 1. Polyhedral clusters and fundamental building-blocks. Can Mineral, 1995, 33: 1131-1151

62 Touboul M, Penin N, Nowogrocki G. Borates: A survey of main trends concerning crystal-chemistry, polymorphism and dehydration process of alkaline and pseudo-alkaline borates. Solid State Sci, 2003, 5: 1327-1342

63 Lei BH, Yang Z, Yu H, et al. Module-guided design scheme for deep-ultraviolet nonlinear optical materials. J Am Chem Soc, 2018, 140: 10726-10733

64 Zhang M, An D, Hu C, et al. Rational design via synergistic combination leads to an outstanding deep-ultraviolet birefringent $\mathrm{Li}_{2} \mathrm{Na}_{2} \mathrm{~B}_{2} \mathrm{O}_{5}$ material with an unvalued $\mathrm{B}_{2} \mathrm{O}_{5}$ functional gene. J Am Chem Soc, 2018, 141: 3258-3264

65 Jiang $\mathrm{D}$, Wang $\mathrm{Y}, \mathrm{Li} \mathrm{H}$, et al. $\mathrm{BaBOF}_{3}$ : a new aurivillius-like borate containing two types of F atoms. Dalton Trans, 2018, 47: 51575160

66 Chen CT, Wu BC, Jiang, AD, You GM. A new type ultraviolet SHG crystal $\beta-\mathrm{BaB}_{2} \mathrm{O}_{4}$. Sci China B, 1985, 28: 235

Acknowledgements This work was supported by the National Natural Science Foundation of China (51922014, 11774414, 51972336 and 61835014), the Key Research Program of Frontier Sciences, CAS (ZDBSLY-SLH035), Tianshan Innovation Team Program (2018D14001), the Western Light Foundation of CAS (Y92S191301) and Fujian Institute of Innovation, CAS

Author contributions Yang $\mathrm{Z}$ designed the concept and wrote the paper; Yang Z, Tudi A, and Lei BH performed the theoretical data analysis; Yang $\mathrm{Z}$ and Pan $\mathrm{S}$ supervised the theoretical data and the paper. All authors contributed to the general discussion.

Conflict of interest The authors declare that they have no conflict of interest.

Supplementary information Electronic supplementary information (ESI) are available in the online version of the paper. 


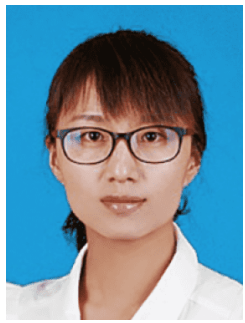

Zhihuang Yang completed her $\mathrm{PhD}$ under the supervision of Professor Jianhui Dai at Zhejiang University in 2008. From 2009 to 2011, she was a post-doctoral fellow at Sungkyunkwan University in Korea. Since 2011, she has been working as a full professor at Xinjiang Technical Institute of Physics \& Chemistry, Chinese Academy of Sciences (XTIPC, CAS). Her current research interests include the response mechanism, structure prediction, design and synthesis of new optical-electronic functional materials.

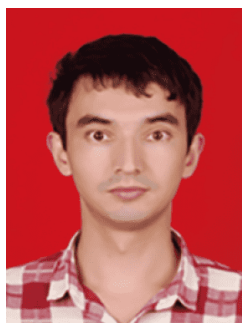

Abudukadi Tudi received his BSc degree in Suzhou University of Science and Technology in 2017. Now, he is a master student at XTIPC, CAS. He is currently focusing on the design and synthesis of optical materials.

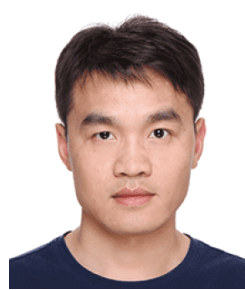

Bing-Hua Lei has accomplished $\mathrm{PhD}$ degree requirements from XTIPC, CAS and is doing a postdoctoral appointment in the Department of Physics and Astronomy at the University of Missouri in Columbia, Missouri. Areas of interest include physics, material science and nonlinear optical materials.

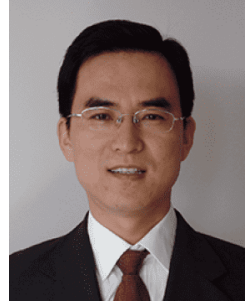

Shilie Pan completed his $\mathrm{PhD}$ under the supervision of Professor Yicheng Wu (Academician) at the University of Science \& Technology of China in 2002. From 2002 to 2004, he was a postdoctoral fellow at the Technical Institute of Physics \& Chemistry of CAS in the laboratory of Professor Chuangtian Chen (Academician). From 2004 to 2007, he was a post-doctoral fellow at Northwestern University in the laboratory of Professor Kenneth R. Poeppelmeier in USA. From 2007, he has been working as a full professor at XTIPC, CAS. His current research interests include the design, synthesis, crystal growth and evaluation of new optical-electronic functional materials.

\section{深紫外氟化硼酸盐双折射率和折射率色散的性能 增益研究}

杨志华 ${ }^{1,2^{*}}$, 阿布都卡地·吐地 ${ }^{1,2}$, 雷兵华 ${ }^{1,2}$, 潘世烈 ${ }^{1,2^{*}}$

摘要 作为紫外/深紫外非线性光学材料的潜在体系, 氟化嗍酸盐 已引起了该领域的广泛关注. 鉴于该类体系中双折射和折射率色 散的影响因素尚未明确, 我们设计了可能的氟化嗍酸盐基团, 分析 了光学各向异性以探索其对双折射率的影响. 通过响应电荷分布 各向异性近似, 我们进一步证明和篎选了有利于双折射率的微观 基团, 并系统地探讨了可有效调节双折射率的功能模块. 基于发展 的折射率色散分析方法, 我们发现氟化硼酸盐基团的引入有利于 降低该类体系在深紫外区的折射率色散, 从而获得较短的相位匹 配波长. 该研究为功能驱动的材料设计提供了一条途径. 